\title{
PROGRAMA NACIONAL DE SERVIÇOS BÁSICOS DE SAÚDE (PREVSAÚDE)
}

O PREVSAUUDE, segundo seu anteprojeto, visa a reordenar o modelo da prestação de serviços do setor, para adequá-lo às necessidades prioritárias da população e aos meios disponíveis para custeá-1o. Representa uma adaptação à problemática deste País daquelas diretrizes traçadas na Conferência da OMS em Alma-Ata, no ano de 1978, que deu ênfase à assistência primária e à extensão de cobertura. E ainda, decorridos seis anos desde a Leí n. ${ }^{\circ} 6229$, de 1975, que cria o Sistema Nacional de Saúde, certas áreas de Estados brasileiros adquiriram alguma experiência de pôr em execução, em áreas limitadas, programas de saúde com a diretriz da OMS, acima citada. As segutintes iniciativas, tomadas nestes últimos anos, são experiências, a saber: unificação das atividades de assistência à saúde no âmbito da Previdência Social, constitu. indo-se o INAMPS; a criação do PLANASA, no âmbito do saneamento básico; o funcionamento da CEME, na assistência farmacêutica; a criação do $F A S$ (Fundo de Apoio ao Desenvolvimento Social); o advento dos grandes prógramas PIASS(1) e PRONAM, além de outras iniciativas de governos de Estados e de entidades particulares. Todas essas experiências servirão para o trabaliho do novo modelo.

Por outro lado, o Governo Federal, por seus dcris Ministérios: da Saúde e da Previdêncila e Assistência Social, teria de melhorar a politica no setor, de vez que, com o predomínio atual das ações de recuperação em detrimento da integralização dos cưidados à saúde e da atenção de nível primário, o aumento de custos e gastos está a exigir uma orientação que leve em conta esta parte financeira, comparada com os benefícios à maioria dos brasileiros.

\section{ENFERMAGEM E O PREVSAUUDE}

PREVSAUDE, ao se referir aos serviços às pessoas, emprega os termos no Attendimento Primário, por exemplo, designando de serviço "médica-odontológico" significando, contudo, no "serviço médico" todo a interdisctiplinaridade que é encontrada na prática atual englobando medicina, biologia médica, enfermagem, nutrição, serviço social e outras. Em uma ou outra parte, re. dações deveriam ser melhoradas, uma vez que as sociedades quando industriais, e não mais essencialmente agropostoris, ocasionam na língua certa precisão que favorece comunicação sem dúvidas. Por exemplo, no anteprojeto há emprego de uma só expressão para significar coisas que diferem entre si. Isto pode ser corrigido. Aliás, na fase de anteprojeto, os Ministérios da Pre-

(1) Vide o Editorial da RBEn, out./dez. 1976. 
vidência e Assistência Social e da Saúde têm declarado que desejam sugestões para seu aperfeiçoamento.

Vejamos os TIPOS de UNIDADES e o ELENCO de ATIVIDADES.

" $A$ estrutura da rede assistencial do PREVSAUDE é composta por unidades produtoras de serviços, cujo porte, perfis funcionais, equipes de saúde, equipamentos, variam.

$\mathrm{Na}$ definição dos vários tipos de unidades que integram a rede do $P R E V$. SAUDE, deve-se buscar caracterizar um módulo mínimo de atividades, pro. vido de recursos para cada uma delas. As unidades poderão compreender um ou mais módulos, em função da cobertura populacional que devem prover. São dados, a seguir, os típos de Unidades.

a) Unidade Elementar ou Posto de Saúde

E a unidade sanitária mais simples, operada por atendente especialmente treinado para execução das ações básicas de saúde, pertinentes à atenção elementar do nível primário. Apoia o sistema informal (agentes de comunidade), em áreas de população dispersa ou de pequenos núcleos.

b) Unidades Ambulatoriais

E o conjunto de unidades sanitárias que têm como característica comum - atendimento médico permanente, variando sua complexidade e dimensões em função da magnitude da população a qưe serve, podenđo chegar até a atendimento emergencial e de nível secundário.

c) Unidades de Internação

E o conjunto de estabelecimentos que têm como caracteristica comum o atendimento com internação variando em complexidade desde a Unidade $M$ ista até os Hospitais Especializados, incluindo-se Hospitais Locais, Regionais e de Base.

$O$ elenco de atividades é descrito a seguir. Em primeiro lugar, de acordo com os tipos de Unidade, em que: 1) Agentes Comunitátios desempenharão, sob orientação e supervisão, atividades elementares, tais como: notificação de casos suspeitos, imunizações, coleta de dados, educação para a saúde e ações para melhoria do ambiente; e 2) Unidades, referidas como Unidades Elementares, Unidades Ambulatoriais, Unidades Mistas e Hospitais Gerais e Hospitais Especializados, cada urma com suas ações próprias. Em segundo lugar, o trabalho de programas de saúde é descrito segundo Áreas Programáticas.

O PREVSAUDE trata a seguir de Recursos Humanos, Sistemas de Apoio e Estudos e Pesquisas, explicitando com certo detalhe cada um destes três capítulos. Finalmente, o anteprojeto do PREVSAÚDE inclui duas partes que estão por último, mas não são as últimas em importância. São elas: 1) Estratéglia do Desenvolvimento do Programa e 2) Metas, Custos e Financiamento.

$A$ Associação Brasileira de Enfermagem reúne-se a outros setores da vida nacional qư têm sua atenção voltada para o PREVSAUDE. Colaborará no que the compete para que um dia as ações básicas de saúde possam beneficiar camadas mais numerosas da população brasileira. A primeira colaboração é justamente a de divulgar o documento, para que os seus associados possam procurá-lo em suas cidades, estudá-lo com espírito crítico e enviar à sede da Associação suas contribuições valiosas.

(HGD) 